УДК 621.438-714

\author{
А. М. РАДЧЕНКО ${ }^{1}$, Р. М. РАДЧЕНКО ${ }^{1}$, С. А. КАНТОР ${ }^{2}$, \\ Б. С. ПОРТНОЙ ${ }^{1}$ В. С. ТКАЧЕНКО
}

${ }^{1}$ Національний університет кораблебудування ім. адм. Макарова, Украӥна

${ }^{2}$ ПАТ "Завод "Екватор", Украӥна

\title{
ОХОЛОДЖЕННЯ ПОВІТРЯ НА ВХОДІ ГТУ З ВИКОРИСТАННЯМ РЕЗЕРВУ ХОЛОДОПРОДУКТИВНОСТІ АБСОРБЦЙНОЇ ХОЛОДИЛЬНОӤ МАШИНИ В БУСТЕРНОМУ ПОВІТРООХОЛОДЖУВАЧІ
}

\begin{abstract}
Досліджено процеси охолодження повітря на вході газотурбінної установки абсорбційною бромистолітієвою холодильною машиною, щчо використовує скидну теплоту відпрацьованих газів, отримано дані з поточних витрат і резерву холодопродуктивності, який утворюється при знижених теплових навантаженнях на повітроохолоджувач. За результатами аналізу отриманих даних 3 поточних теплових навантажень на повітроохолоджувач обтрунтовано доцільність використання резерву холодопродуктивності для попереднього охолодження повітря в бустерному ступені при підвищених теплових навантаженнях на повітроохолоджувач з метою скорочення встановленої холодопродуктивності абсорбиійної холодильної машини.
\end{abstract}

Ключові слова: охолодження, повітря, теплове навантаження, бустерний повітроохолоджувач, абсорбиійна холодильна машина.

\section{1. Аналіз проблеми і постановка мети дослідження}

Охолодження повітря на вході газотурбінних установок (ГТУ) тепловикористовуючими холодильними машинами (ТХM), що трансформують в холод теплоту відпрацьованих газів, є одним з основних напрямів підвищення їх ефективності. В найбільш поширених абсорбційних бромистолітієвих холодильних машинах (АБХМ) повітря можна охолоджувати до температури $t_{\mathrm{B} 2} \approx 15^{\circ} \mathrm{C} 3$ високою ефективністю трансформації скидної теплоти в холод: їх тепловий коефіцієнт $\zeta=0,7 \ldots 0,8[1,2]$. Більш глибоке охолодження повітря до температури $t_{\mathrm{B} 2}=10^{\circ} \mathrm{C}$ і нижче можливе в ежекторних холодильних машинах (ЕХM), ефективність трансформації скидної теплоти в холод в яких значно менше: $\zeta=$ $0,2 \ldots 0,3$ [3]. То ж доцільним є двоступеневе охолодження повітря на вході ГТУ: до $t_{\mathrm{B} 2}=15 \ldots 20^{\circ} \mathrm{C}$ в АБХМ, а до $t_{\mathrm{B} 2}=7 \ldots 10^{\circ} \mathrm{C}$ в ЕХМ. Відповідно до поточних тепловологісних параметрів зовнішнього повітря суттєво змінюється теплове навантаження на повітроохолоджувачі (ПО), відповідно й витрати холодопродуктивності перш за все АБХМ і лише при низькій температурі навколишнього повітря $t_{\mathrm{Hв}} \leq 10^{\circ} \mathrm{C}$ ще й ЕХМ. При знижених теплових навантаженнях утворюється резерв холодопродуктивності передусім АБХМ (надлишок порівняно зі встановленою-проектною), який доцільно використовувати для покриття іiі дефіциту при підвищених нава- нтаженнях, завдяки чому зменшити встановлену холодопродуктивність і вартість АБХМ.

Мета дослідження - аналіз даних з резерву холодопродуктивності АБХМ при знижених теплових навантаженнях на ПО на вході ГТУ та його використання у бустерному ступені попереднього охолодження повітря зі скороченням встановленої холодопродуктивності АБХМ.

\section{2. Результати дослідження}

Резерв встановленої (проектної) холодопродуктивності АБХМ, який утворюється при знижених теплових навантаженнях, визначають як ії надлишок порівняно 3 поточним сумарним тепловим навантаженням базового високотемпературного ступеня ПО $\mathrm{O}_{\mathrm{BT}}$ i бустерного ступеня ПО попереднього охолодження повітря за рахунок резерву холодопродуктивності АБХМ, тобто теплообмінника "ПО Вт + ПО $"$ ".

Проектне теплове навантаження на ПО визначають як $Q_{0 . \text { вт17пр }}=q_{0 . \text { вТ17пр }} \cdot G_{\text {п }}=17 \cdot 40=$ 680 кВт, виходячи 3 прийнятого питомого (при витраті повітря $\left.G_{\text {п }}=1 \cdot \kappa \Gamma / \mathrm{c}\right)$ теплового навантаження ПО повітря через ПО Вт . При цьому проектне теплове навантаження на ПО визначають як $Q_{0 . \text { Вт24пр }}=q_{0 . \text { ВТ24пр }} \cdot G_{\text {п }}=24 \cdot 40=$ 960 кВт, де $q_{0 . \text { вт24пр }} \cdot=24$ кВт(кг/с) - загальне питоме теплове навантаження обох повітроохолоджувачів 
ПО максимального ефекту від охолодження (наприклад річної економії палива) при охолодженні повітря на вході ГТУ до температури $t_{\text {в2 }} \approx 15^{\circ} \mathrm{C}$ в АБХМ [3].

При визначенні резерву холодопродуктивності АБХМ поточне теплове навантаження на ПО бустерним ПО б порівнюють 3 проектним тепловим навантаженням $Q_{0 \text { вт24пр }}=q_{0 . \text { ВТ24пр }} \cdot G_{\text {п }}=24 \cdot 40=$ $=960$ кВт, де $q_{0 . \text { вт24пр }}=24$ кВт(кг/с).

Схема системи охолодження повітря на вході ГТУ 3 використанням резервної холодопродуктивності АБХМ у бустерному ступені ПОб попереднього охолодження показана на рис. 1 .

Заміщення (часткове) високотемпературного ступеня ПО леної холодопродуктивності АБХМ можливе за наявності резерву холодопродуктивності, який перевищує їі витрати на попереднє охолодження повітря на вході високотемпературного ступеня повітроохоло-

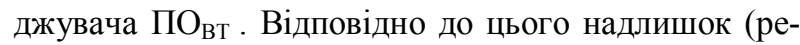
зерв) холодопродуктивності АБХМ визначають як $Q_{0 . \text { вТ17изб }}=Q_{0 . \text { ВТ17пр }}-Q_{0 . \text { ВТ24 }}=680-Q_{0 . \text { ВТ24 }}$, кВт, а ії дефіцит відповідно: $Q_{0 . \text { вт17д }}=Q_{0 . \text { вт24 }}-Q_{0 . \text { вТ17пр }}=$ $Q_{0 . \text { вт24 }}-680$, кВт. Ці баланси співпадають за умови правильно підібраного проектного сумарного теплового навантаження ПО попереднього охолодження повітря за рахунок резерву холодопродуктивності АБХМ. Однак сама величина резерву холодопродуктивності залежить від конкретних кліматичних умов і проміжку часу, взятого для його визначення. То ж мова може йти про вибір умовно раціональної ії величини, виходячи 3 надлишку (резерву) холодопродуктивності, накопиченого упродовж певного періоду. Про наближення до неї свідчить зближення надлишку холодопродуктивності з його дефіцитом для охолодження повітря в ПО мінниках "ПО

Приклад реалізації зазначеного підходу до визначення ефекту від застосування бустерного ступеня ПОб п попереднього охолодження у вигляді зменшення встановленої холодопродуктивності АБХМ, по суті - визначення проектного теплового

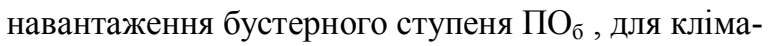

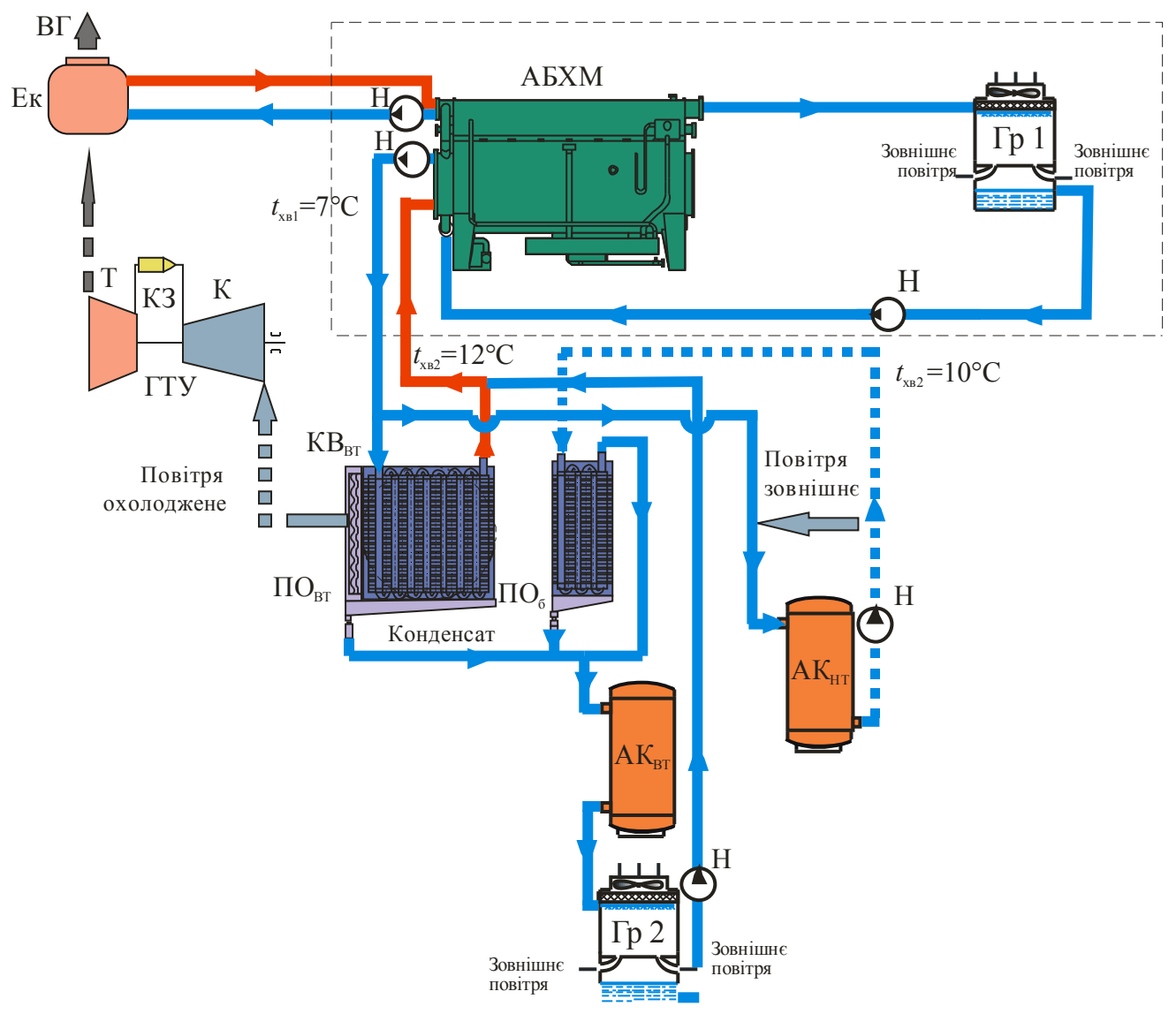

Рис. 1. Принципова схема системи охолодження повітря на вході ГТУ з використанням резервної холодопродуктивності АБХМ у бустерному ступені ПО б : К - компресор; Т - турбіна; КЗ - камера згоряння;

Н - насос; ВГ - відпрацьовані гази; Ек - экономайзер нагріву води для АБХМ; ПО

i ПО акумулятори конденсату 
тичних умов м. Южноукраїнськ, Миколаївська обл., упродовж 10 діб (1-10.07.2015) наведено на рис. $2,3$.

При цьому на рис. 2 наведено поточні теплові навантаження $Q_{0 . \text { вт24 }}$ на ПО вт 3 бустерним ПО також відповідні надлишок (резерв) $Q_{0 . в т 17 и з б ~}$ i

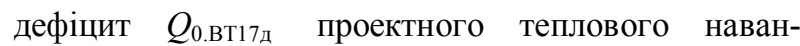

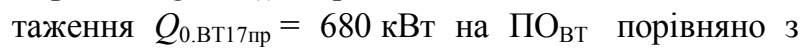
поточним тепловим навантаженням $Q_{0.8 т 24}$ та відповідні сумарні по нарощуванню за 10 діб надлишок (резерв) $\sum Q_{0 . \text { вт17изб }}$ і дефіцит $\sum Q_{0 . \text { вт17д }}$ проектного теплового навантаження без використання резерву холодопродуктивності АБХМ в бустерному ПОб .

Як видно 3 рис. 2, сумарний за 10 діб (1-10.07.2015) надлишок (резерв) холодопродуктив-

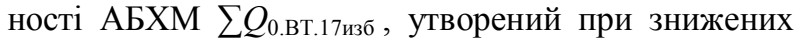

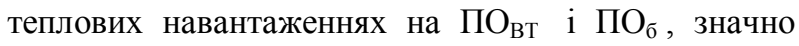

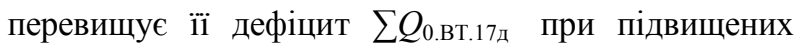
теплових навантаженнях. При цьому помітний дефіцит холодопродуктивності АБХМ має місце, починаючи з 6.07.2015, коли поточні теплові навантаження $Q_{0 . \text { вт24 }}$ більше $Q_{0 . \text { вт17пр }}=680$ кВт.

Як видно, використанням резерву холодопродуктивності АБХМ у бустерному ступені ПО безпечує скорочення встановленої холодопродуктивності АБХМ на величину проектного теплового навантаження $Q_{0.7 \text { пр }}=q_{0.7 \text { пр }} \cdot G_{\text {п }}=7 \cdot 40=280$ кВт, тобто на $25 \ldots 30 \%$ порівняно 3 базовим $Q_{0 . \text { вт24пр }}=$ $=q_{0 . \text { ВТ24пр }} \cdot G_{\text {пा }}=24 \cdot 40=960$ кВТ на ПО ВТ $3 \Pi_{\sigma}$.

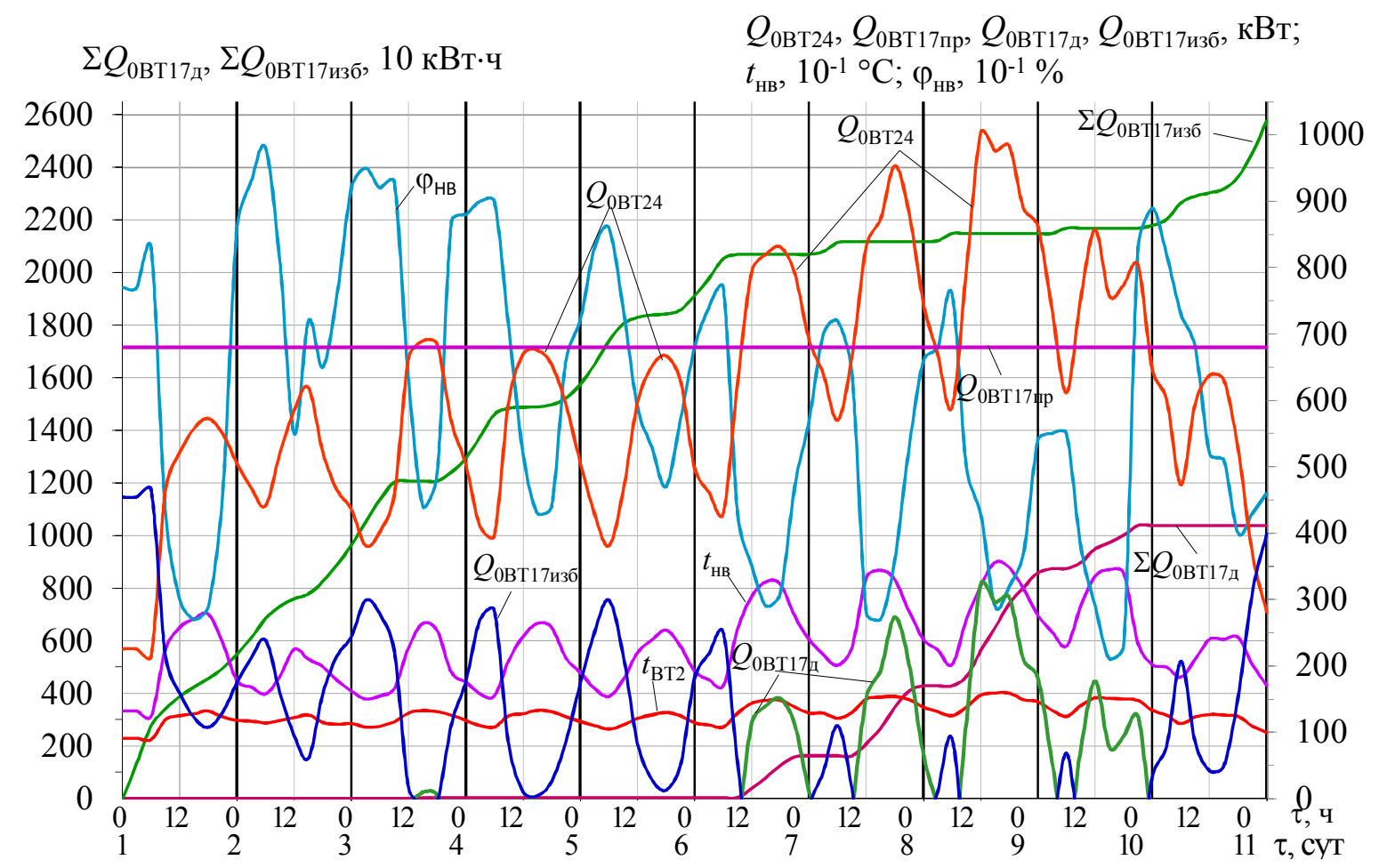

Рис. 2. Поточні значення температури $t_{\text {нв }}$ і відносної вологості $\varphi_{\text {нв }}$ навколишнього повітря,

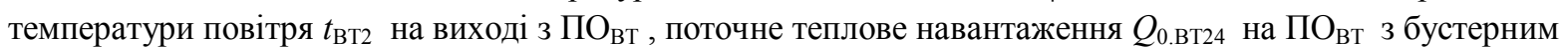
ПО б (витрати холодопродуктивності АБХМ без використання їі резерву в бустерному ПО б ), надлишок

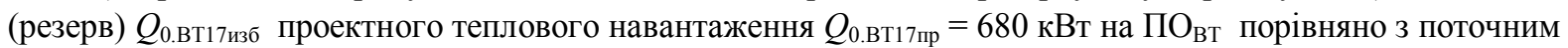
тепловим навантаженням $Q_{0 . \mathrm{BT} 24}$ на ПО холодопродуктивності АБХМ), дефіцит $Q_{0 . \text { вТ17д }}$ проектного теплового навантаження $Q_{0 . \mathrm{BT} 17 \text { пр }}=680$ кВТ на ПО Вт порівняно з поточним тепловим навантаженням $Q_{0.8 т 24}$, сумарні по нарощуванню за 10 діб надли-

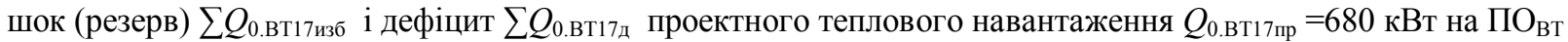
порівняно з поточним тепловим навантаженням $Q_{0.8 т 24}$ на ПО ${ }_{\text {вт }}$ бустерним ПО б без акумуляції і використання резерву холодопродуктивності АБХМ (витрата повітря 40 кг/с) упродовж 10 діб (1-10.07.2015, м. Южноукраїнськ, Миколаївська обл.) 


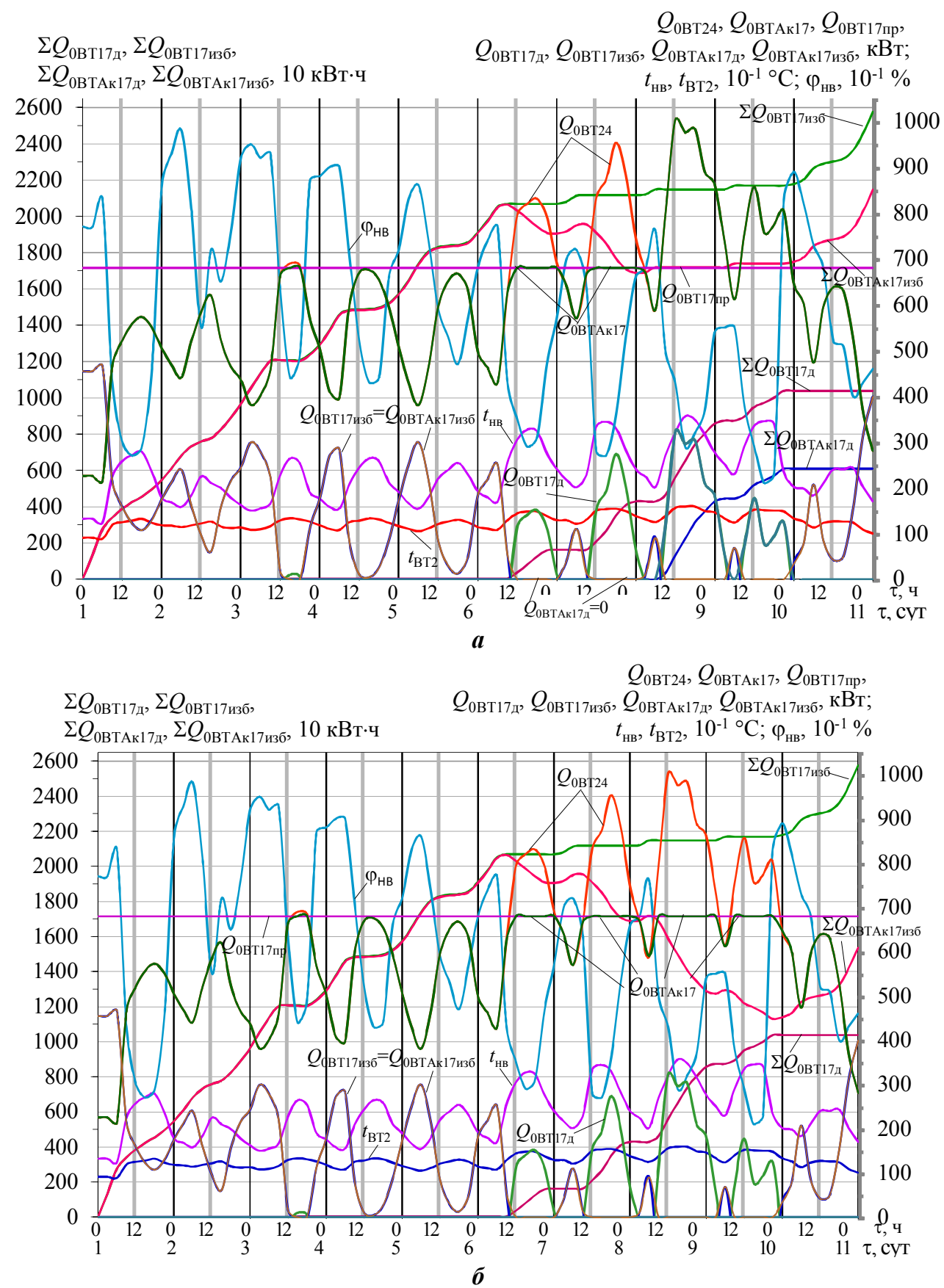

Рис. 3. Поточні значення температури $t_{\text {нв }}$ і відносної вологості $\varphi_{\text {нв }}$ навколишнього повітря, температури повітря $t_{\mathrm{BT} 2}$ на виході ПО навантаження $Q_{0 . \text { втАк17 }}$ на ПО Вт (без врахування бустерного ПО

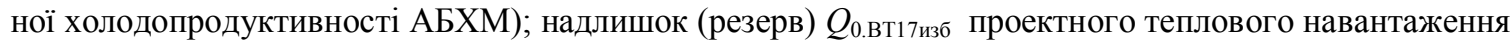
$Q_{0 . \text { вт17пр }}=680$ кВт порівняно 3 поточним тепловим навантаженням $Q_{0 . \text { вт24 }}$ на ПО вт $з$ бустерним ПО

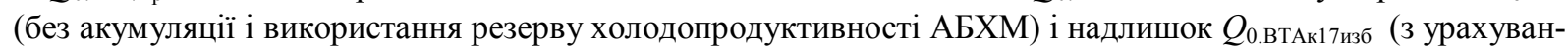
ням його зменшення на використання резерву холодопродуктивності АБХМ в ПО б ), дефіцит $Q_{0 . \text { вт17д }}$ проектного теплового навантаження $Q_{0 . \text { вт17пр }}=680$ кВт на ПО Вт порівняно з поточним тепловим навантаженням $Q_{0 . \text { вт24 на ПО }}$ Вт з бустерним ПО

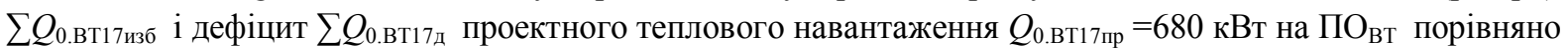
3 поточним тепловим навантаженням $Q_{0.8 т 24}$ на ПО вт $_{3}$ бустерним ПО без використання резерву холодопродуктивності АБХМ в ПОб та надлишок (резерв) $\sum Q_{0 . \text { вТАк17изб }}$ і дефіцит $\sum Q_{0 . \text { втАк17д }}$ 3 урахуванням їх зменшення на використання резерву холодопродуктивності АБХМ в ПО (витрата повітря 40 кг/с) упродовж 10 діб (1-10.07.2015, м. Южноукраїнськ, Миколаївська обл.): $\boldsymbol{a}$ - 3, 6 і 7.07.2015 p.;

$$
\text { б - 3, 6-9.07.2015 p. }\left(Q_{0 . \text { ВТАк17д }}=0 ; \sum Q_{0 . \text { ВТАк17д }}=0\right)
$$


Як видно 3 порівняння даних на рис. 3, a і б, по мірі використання резерву холодопродуктивності АБХМ в бустерному ступені ПО б послідовно 6,7,8 i 9.07.2015 усувається сумарний дефіцит $\sum Q_{0 . \text { вТАк17д }}$, тобто встановленої холодопродуктивності АБХМ $Q_{0 . \text { ВТ17пр }}=680$ кВт стає достатньо для покриття поточних теплових навантажень. При цьому відповідно зменшується й надлишок встановленої холодопродуктивності АБХМ $\sum Q_{0 . \text { ВТАк17изб }}$ від 2600 кВТ (рис.2) до 1500 кВт (рис.3,б). Наявність все ж значного надлишку холодопродуктивності АБХМ свідчить про можливість його подальшого скорочення шляхом зменшення встановленої холодопродуктивності АБХМ з іiі заміщенням закумульованим охолоджувальним потенціалом, тобто перекладанням іiі теплового навантаження на бустерний ступінь попереднього охолодження.

\section{Висновки}

Обгрунтовано доцільність застосування бустерного ступеня попереднього охолодження повітря на вході ГТУ шляхом використання резерву холодопродуктивності АБХМ, який завдяки адаптації до поточних кліматичних умов забезпечує зменшення на $25 \ldots 30 \%$ встановленої холодопродуктивності, відповідно і вартості АБХМ.

\section{Литература}

1. Popli, S. Trigeneration scheme for energy efficiency enhancement in a natural gas processing plant through turbine exhaust gas waste heat utilization [Text] / Sahil Popli, Peter Rodgers, Valerie Eveloy // Applied Energy. - 2012. - № 93. - P. 623-636.
2. Popli, S. Gas turbine efficiency enhancement using waste heat powered absorption chillers in the oil and gas industry [Text]/ Sahil Popli, Peter Rodgers, Valerie Eveloy // Applied Thermal Engineering. - 2013. - № 50. - P. 918-931.

3. Радченко, А. Н. Метод выбора рацииональной тепловой нагрузки абсорбичонно-эжекторного термотрансформатора охлаждения воздуха на входе регенеративных ГТУ компрессорных станций [Текст] / A. Н. Радченко, С. А. Кантор // Авиачионно-космическая техника и технология. - 2015. - № 5(122). - C. 61-64.

\section{References}

1. Popli, Sahil., Rodgers, Peter., Eveloy, Valerie. Trigeneration scheme for energy efficiency enhancement in a natural gas processing plant through turbine exhaust gas waste heat utilization. Applied Energy, 2012, no. 93, pp. 623-636.

2. Popli, Sahil., Rodgers, Peter., Eveloy, Valerie. Gas turbine efficiency enhancement using waste heat powered absorption chillers in the oil and gas industry. Applied Thermal Engineering, 2013, no. 50, pp. 918931.

3. Radchenko, A. N., Kantor, S. A. Metod vybora racionalnoy teplovoy nagruzky absorbcionnoezhektornogo termotransformatora okhlazhdeniya vozdukha na vhode regenerativnyh GTU kompressornyh stanciy [The method of evaluation of rational heat load on absorption-ejector thermotransformer for cooling regenerative GTU intake air of compressor stations]. Avitsionno-kosmicheskaya tehnika $i$ tehnologiyaAerospace technics and technology, 2015, no. 5 (122), pp. 61-64.

\section{Поступила в редакцию 17.12.2017, рассмотрена на редколлегии 14.02.2018}

\section{ОХЛАЖДЕНИЕ ВОЗДУХА НА ВХОДЕ ГТУ С ИСПОЛЬЗОВАНИЕМ РЕЗЕРВА ХОЛОДОПРОИЗВОДИТЕЛЬНОСТИ АБСОРБЦИОННОЙ ХОЛОДИЛЬНОЙ МАШИНЫ В БУСТЕРНОМ ВОЗДУХООХЛАДИТЕЛЕ}

\section{А. Н. Радченко, Р. Н. Радченко, С. А. Кантор, Б. С. Портной, В. С. Ткаченко}

Исследованы процессы охлаждения воздуха на входе газотурбинной установки абсорбционной бромистолитиевой холодильной машиной, использующей сбросную теплоту отработавших газов, получены данные по текущим расходам и резерву холодопроизводительности, который образуется при пониженных тепловых нагрузках на воздухоохладитель. В результате анализа полученных данных по текущим тепловым нагрузкам на воздухоохладитель обоснована целесообразность использования резерва холодопроизводительности для предварительного охлаждения воздуха в бустерной ступени при повышенных тепловых нагрузках на воздухоохладитель с целью сокращения установленной холодопроизводительности абсорбционной холодильной машины.

Ключевые слова: охлаждение, воздух, тепловая нагрузка, бустерный воздухоохладитель, абсорбционная холодильная машина. 


\title{
GAS TURBINE UNITE INLET AIR COOLING BY USING AN EXCESSIVE REFRIGERATION CAPACITY OF ABSORPTION CHILLER IN BUSTER AIR COOLER
}

\author{
A. N. Radchenko, R. N. Radchenko, S. A. Kantor, B. S. Portnoy, V. S. Tkachenko
}

The processes of gas turbine unit inlet air cooling by absorption lithium-bromide chiller utilizing the turbine exhaust gas waste heat as a thermotransformer has been analyzed for hour-by-hour changing ambient air temperatures and changeable heat loads on the air cooler as consequence. The computer programs of the firms-producers of heat exchangers were used for gas turbine unit inlet air cooling processes simulation. It is shown that at decreased heat loads on the air cooler an excessive refrigeration capacity of the absorption lithium-bromide chiller exceeding current heat loads is generated which can be used for covering increased heat loads on the air cooler and to reduce the refrigeration capacity of the absorption lithium-bromide chiller applied. To solve this task the refrigeration capacity required for gas turbine unit inlet air cooling is compared with an excessive refrigeration capacity of the absorption lithium-bromide chiller exceeding current heat loads summarized during 10 days of July 2015.

The system of gas turbine unit inlet air cooling with a buster stage of precooling air and a base stage of cooling air to the temperature of about $15^{\circ} \mathrm{C}$ by absorption lithium-bromide chiller has been proposed. An excessive refrigeration capacity of the absorption chiller generated during decreased heat loads on the gas turbine unit inlet air cooler that is collected in the thermal accumulator is used for gas turbine unit inlet air precooling in a buster stage of air cooler during increased heat loads on the air cooler. The results of gas turbine unit inlet air cooling processes simulation proved the reduction of refrigeration capacity of the absorption lithium-bromide chiller applied by 30 $40 \%$ due to the use of a buster stage of precooling air at the expanse of an excessive absorption chiller refrigeration capacity served in the thermal accumulator. So the conclusion has been made about the efficient use of a buster stage of gas turbine unit inlet air cooler for precooling air by using an excessive refrigeration potential of absorption lithium-bromide chiller coolant saved in the thermal accumulator.

Keywords: cooling, air, heat load, buster air cooler, absorption chiller.

Радченко Андрій Миколайович - канд. техн. наук, доц., Національний університет кораблебудування ім. адмірала Макарова, Миколаїв, Україна, e-mail: nirad50@gmail.com.

Радченко Роман Миколайович - канд. техн. наук, доц., Національний університет кораблебудування ім. адмірала Макарова, Миколаїв, Україна, e-mail: nirad50@gmail.com.

Кантор Сергій Анатолійович - канд. техн. наук, ПАТ "Завод "Екватор", Миколаїв, Україна, e-mail: s_kantor@mail.ru.

Портной Богдан Сергійович - аспірант, Національний університет кораблебудування ім. адмірала Макарова, Миколаїв, Україна, е-таil:

Ткаченко Веніамін Сергійович - інженер, ПАТ "Завод "Екватор", Миколаїв, Україна, e-mail: btd@zavod-ekvator.com.

Radchenko Andrey Nikolaevich - PhD, Assistant Professor of Dept. of Ship Electroenergetic Systems, Admiral Makarov National University of Shipbuilding, Mykolaiv, Ukraine, e-mail: nirad50@gmail.com.

Radchenko Roman Nikolaevich - PhD, Assistant Professor of Admiral Makarov National University of Shipbuilding, Mykolaiv, Ukraine, e-mail: nirad50@gmail.com.

Kantor SergeyAnatolievich - PhD, PJSC "Zavod "Ekvator", Mykolaiv, Ukraine, e-mail: s_kantor@mail.ru.

Portnoy Bogdan Sergeevich - PhD Student, Admiral Makarov National University of Shipbuilding, Mykolaiv, Ukraine, e-mail: Tkachenko Veniamin Sergeevich - Engineer, PJSC "Zavod "Ekvator", Mykolaiv, Ukraine, e-mail: btd@zavod-ekvator.com. 